\title{
Pynchon's Against the Day: Bilocation, Duplication, and Differential Repetition
}

\author{
Ali Salami \\ Department of English, University of Tehran, Tehran, Iran \\ Razieh Rahmani \\ Department of English, University of Tehran, Iran
}

\begin{abstract}
In Against the Day, Pynchon is obsessed with twoness, double worlds, as well as dual realities, and like Deleuze's concept of repetition, these duplications and twinships are not merely repetition of the same, rather they allow for creativity, reinvention, and becoming. Pynchon's duplication of fictional and spectral characters intends to critique the notion of identity as does Deleuzian concept of repetition. Not attached to the representational concept of identity as the recurrence of the same, Pynchon's duplications decenter the transcendental concept in favor of a perpetual becoming and reproduces difference and singularity. Like Deleuze, Pynchon eschews an identity that is always guaranteed, and shows that the repetition of an object or a subject is not the recurrence of the original self-identical object or person. Moreover, Iceland spar, the mystifying calcite, with its doubling effect provides the reader with a view of a world beyond the ordinary, actual world, which is quite similar to what Pynchon's novel does per se.
\end{abstract}

Index Terms - bilocation, duplication, repetition, difference, double refraction

\section{INTRODUCTION}

"Even if you forget everything else," Rinpungpa instructs the Yogi, "remember one thing - when you come to a fork in the road, take it." Easy for him to say, of course, being two people at once. (Pynchon, 2006, p.766)

In Against the Day, Pynchon reveals his obsession with double worlds, bilocation, and repetition, but not the commonsensical concept of repetition rather the Deleuzian, differential repetition. To Deleuze, repetition is creativity and invention not sameness, difference not habitual reiteration; that is, repetition is not reducible to the repetition of the same which is based on the idea of identity and resemblance, rather it is contingent on difference. Indeed, "difference" and "repetition" are interlocked and integrated. From Deleuzian perspective, the two presents, two scenes, or two events might be successive, "at a variable distance apart", but they are rather

two real series which coexist in relation to a virtual object of another kind [...] It is because this object constantly circulates, always displaced in relation to itself, that it determines transformations of terms and modifications of imaginary relations within the two real series in which it appears, and therefore between the two presents (Deleuze, 1994, p. 105).

Simply put, when one thing repeats itself, although we have "two presents [that] are successive," it is an illusion to consider one as the copy of another or consider one more real than the other since both possess a virtual force and a singularity to itself. In fact, Deleuze criticizes the traditional, totalizing, and homogenizing approach to repetition. To him, repetition is not redundancy or habitual recognition of the same; quite the opposite, it is essentially creative and productive of difference. In other words, only difference is repeated, and only difference returns (akin to Nietzsche's "eternal return"1). To Deleuze repetition functions as a critique of representation ${ }^{2}$, as well as identity.

We have tried to show that it is a question of simulacra, and simulacra alone. The power of simulacra is such that they essentially implicate at once the object $=\mathrm{x}$ in the unconscious, the word $=\mathrm{x}$ in language, and the action $=\mathrm{x}$ in history. Simulacra are those systems in which different relates to different by means of difference itself. What is essential is that we find in these systems no prior identity, no internal resemblance. It is all a matter of difference in the series, and of differences of difference in the communication between series. (Deleuze, 1994, p. 299)

Arguably, Pynchon's Against the Day is replete with bilocation, duality, and bifurcation implying the omnipresence powers of repetition and difference, and transcending the actual realm. In the novel, dual refraction opens the actual world to the virtuality by the duplication, triplication, and even multiplication of possibility. The novel, as such, seems to be a calcite with the ability of double refraction, having two Chums of Chance, Chums and their Russian double The Bol'shaia Igr; two Stupendicas, Stupendica and Emperor Maximillian; multiple twin characters such as Dr. Werfner and

\footnotetext{
${ }^{1}$ To Deleuze, Nietzsche's concept of eternal return is "the fundamental axiom of a philosophy of forces in which active force separates itself from and supplants reactive force and ultimately locates itself as the motor principle of becoming" (Spinks, 2012, p. 86).

2 Deleuze criticizes Freud's conception of repetition; he believes Freud reduces repetition to representation by confining it to a compulsive reiteration of the past (Parr, 2012, p. 224). Deleuze (1994) argues that difference is not contingent on representation; "Difference is not and cannot be thought in itself, so long as it is subject to the requirements of representation" (Deleuze, p. 262).
} 
Dr. Renfrew; multiple Shambhalas; two Earths, "our" Earth and Counter-Earth; two Venices, "Venice of the Low Countries" and contra-Veneziai or "Venice of the Arctic" (Pynchon, 2006, p.136); ${ }^{3}$ two New Yorks, New York and its doppelganger; and many other different manifestations of the same person, same event, or same place. As Elias (2011) aptly points out, "As in picaresque understood as romance, Pynchon's novel doubles and mirrors characters and scenes" (p. 31). Moreover, due to the operation of light refraction, several possible alternatives are given for some actual event of the novel and some of those actual events of history that are referenced in the novel.

\section{DISCUSSION}

It is noteworthy that out of the five chapters of the novel, one (chapter three) is entitled "Bilocations" which implies parallel worlds and the experience of being at two different places or dimensions at the same time. Nevertheless, the theme of pairings, twonesses, and alternate versions is reverberated in the whole novel; as Paul Narkunas (2011) argues, characters "throughout Against the Day are doubled and mirrored to disturb further this national space-time, and therefore the theme of bilocation figures prominently" (p. 242). Pynchon's propensity for twoness is comparable to that of his character Lindsay Noseworth. Lindsay, who is afflicted with the symptoms of "Incipient Gamomania" i.e., an "abnormal desire to be married" (Against p. 432), says, "my governing desire in life is to be no longer one, but two, a two which is, moreover, one - that is, denumerably two" (Against p. 432).

Pynchon's plurality of possibilities leaves us with a pluralized universe which is a transcendent flight from mundane existence of the actual realm. This tendency for differential repetition allows for the possibility of being exposed to the hidden, virtual worlds; Kit, pondering over the mysterious nature of light, states, "Double refraction appears again and again as a key element, permitting a view into a Creation set just to the side of this one, so close as to overlap, where the membrane between the worlds [...] has become [...] frail" (Against p. 566). In "Binocular Disparity and Pynchon's Panoramic Paradigm", Clair refers to the differential power of repetition; he quotes parrot's conversation with Frank in which the parrot says,

"Think! Double refraction! Your favorite optical property! Silver mines, full of espato double-refracting all the time, and not only light rays, naw, uh-uh! Cities, too! People! Parrots! [...] you don't see those strange lights all around you. Ay, Chihuahua. In fact, Ay, Chihuahua, Chihuahua" (Against p. 387).

Clair (2011) believes this exchange is more than a comedic aside and that the bird which is famed for "its powers of repetition", "attempts to transcend mere repetition by presenting a case for the omnipresence of repetition" (p.78). Besides, in the novel, Zombini, the magician, is able to duplicate people using Iceland spar. However, according to Deleuzian concept of repetition and difference, the only thing that is repeated is difference; hence, the two duplicated persons will be two different people with different paths in life as "To repeat is to begin again; to affirm the power of the new and the unforeseeable" (Parr, 2012, p. 225). Here, Zombini is explaining to his daughter the repletion of difference that transpires in the process of duplication:

"Is it a happy ending. Do they go back to being one person again?" [...]

"No, and that's been kind of a running problem here. Nobody can figure out [...] how to reverse it. I've been everywhere, asked everybody, college professors, people in the business, even Harry Houdini himself, no dice [...]. It was an optical problem, I thought it would be completely reversible. But according to Professor Vanderjuice up at Yale, I forgot the element of time, it didn't happen all at once, so there was this short couple of seconds where time went on, irreversible processes of one kind and another, this sort of gap opened up a little, and that was enough to make it impossible to get back to exactly where we'd been." (Against p. 355)

Zombini tells his daughter that he has copied two or three people making four or six different individuals with totally different life paths. What is more, they are unable to go back to unite in one original person because each version turns out to be a differential repetition of the duplicated person not an identical copy; as Colebrook (2002) states, "There is not an original life that is then varied or copied in different versions; each event of life is already other than itself, not original, a simulation" (p. 99). Indeed, this is similar to what Deleuze (1989) describe as "the bursting forth of life, of time, in its dividing in two or differentiation" (p. 88). Interestingly, Zombini explains that this disaster happens because of the element of "time" as the passing of time makes the process irretrievable since, from Deleuzian perspective, repetition is not the return of the past or a repetition of the same. Interestingly, one of the basic concepts of Deleuze is the intricate rapport between time and difference; he always emphasizes that time is difference in itself. Moreover, as with difference, for Deleuze, one of the central concepts in repetition is time. Further, time itself splits itself into past and present, "in two dissymmetrical jets" coexisting as a virtual and actual image: "Time has to split at the same time as it sets itself out or unrolls itself: it splits in two dissymmetrical jets, one of which makes all the present pass on, while the other preserves all the past. Time consists of this split, and it is this, it is time" (Deleuze, 1989, p. 81).

The notion of duplicated and multiple world could also be seen in Werfner's speech regarding the tragedy of Mayerling. When Colonnel Käutsch suggests that in the tragedy, the agent who possibly had killed the Prince Rudolf and his lover, was Jack the Ripper, Werfner suggests that there might have been Hundreds of Jack the Rippers, "Hundreds, by now thousands, of narratives, all equally valid -- what can this mean?" "Multiple worlds," says Nigel. "Precisely!" cries the Professor (Against p. 682). Moreover, Lew Basnight is obsessed with the concept of bilocation

\footnotetext{
${ }^{3}$ Hereafter, I refer to Pynchon's Against the Day (2006) as Against.
} 
too. Once, Dr. Otto Ghloix informs Lew that in order to reach the pure land of Shambhala, he should go through the "secret geographies of the beyul, or hidden lands" using a procedure called "bilocation." The technique is a "strange and useful talent of being two places or more at once, known in the Psychical field for about fifty years as 'bilocation.' North Asian shamans in particular seemed to be noted for it" (Against p. 686). The technique is discovered by Dr. Werfner and/or Dr. Renfrew who are the manifestation of one person's bilocation as such.

Further, identity to Deleuze is a problem caused by being tied to representation and deviating from difference. As Cliff Stangol (2012) states, Deleuzian concept of difference challenges, "the primacy accorded identity and representation in western rationality" (p. 72). Indeed, in Difference and Repetition, Deleuze (1994) intends to undermine the western notion of identity which is based on rational Cogito, the "identical, similar, analogous" Kantian "I" which makes difference an object of representation:

The "I think" is the most general principle of representation - in other words, the source of these elements and of the unity of all these faculties: I conceive, I judge, I imagine, I remember and I perceive ... they form quadripartite fetters under which only that which is identical, similar, analogous or opposed can be considered different: difference becomes an object of representation always in relation to a conceived identity, a judged analogy, an imagined opposition or a perceived similitude. (p. 138)

To Deleuze, Kant's conception of "I" is devoid of "the conditions of a true critique and a true creation" (1994, p. 139), an "I" with the ability of transcendental apperception, an "I" whose identity is contingent on representation and signification, an identity which only gains meaning in relation to "other". Opposite to Kantian persistence on identity, sameness, and representation, in Deleuzian difference, identity is dissolved in "the destruction of an image of thought which presupposes itself and the genesis of the act of thinking in thought itself' (Deleuze, 1994 p. 139).

Thus, the Deleuzian notion of repetition is based on the assumption that we have virtual singularities and actual individuals. ${ }^{4}$ An instance of repetition that leads to singularities, not sameness, could be seen in the pair of Professor Werfner of Göttingen and Professor Renfrew of Cambridge. In London, Lew Basnight along with Neville and Nigel (the British agents, Neville and Nigel or "the Two N's" are another of the novel's comic pairs) goes to watch an intriguing play about "An actor playing an actor playing Jack" where Lew sees a person that Lew thinks is Professor Renfrew. Later, he learns that he is Professor Renfrew's double, Professor Werfner. Lew then realizes that T.W.I.T. and the two N's have hid many things from him including the fact that Renfrew and Werfner are actually one person with a paranormal power:

They were impersonating British idiots. And in that luminous and tarnished instant, he understood, far too late in the ball game, that Renfrew and Werfner were one and the same person... that this person somehow had the paranormal power to be in at least two places at the same time... and that everybody at the T.W.I.T. had known this, known forever, most likely -- everybody except Lew. (Against p. 729)

Lew reads many books on the "talent of being two places or more at once" or "bilocation" some "in languages he didn't even recognize" (Against p. 685). ${ }^{5}$ This practice is an internal journey similar to dreaming "in which one version of you remains behind," and your other version goes serenely off to "worlds unexpected" with paranormal skills such as "flying, passing through walls, performing athletic miracles of speed and strength" (769). This reminds us of Deleuzian idea of repetition that repudiates "Platonist idea of repeating in order to produce copies is completely", an idea that "subsumes the creative nature of difference under an immobile system of resemblance" (Parr, 2012, p. 225). That is, the virtual and mysterious "bilocation" which Werfner /Renfrew is capable of is quite akin to Deleuzian notion of repetition and difference. The narrator says Renfrew is the "opposite number" (Against p. 254) of Werfner, rival scientists with palindromic name whose characters read the same backward. When T.W.I.T employs Lew to spy on them, Nookshaft tells Lew that Werfner and Renfrew have the position of The Devil of the Arcana. Lew is very "willing to accept the two professors as a single person" and feels "curiously released, as if from a servitude he had never fully understood the terms of anyway" (Against p. 771) when he concludes from the evidence that they are the same person. Arguably, this sense of "relief" on the part of Lew stems from his desire to for "identity" and "sameness" as opposed to difference. Lew tend to see the two professors as one rather than two people with two different individualities who have been created out of one individual whose each half is housed in a new body; that is, the result of the mitosis is two different singularities. As Deleuze states, "Repetition and resemblance are different in kind-extremely so" (1994, p.1). In the same vein, despite the stunning similarities, Werfner Renfrew are different in many ways so much so that the two develop an acrimonious rivalry as well as harsh conflicts, and they seem to be each other's opposite image. Generally, from Deleuzian perspective, as differential repetitions, the two can resemble each other and share particular qualities, but they do not repeat one another. That is, one is not a copy or simulacra (in its Baudrillardian sense) of the other as they maintain their own "non-exchangeable and non-substitutable" (Deleuze, 1994, p.1) singularities which are expressed in their differences. Nathalie Aghoro (2009) also states, "Renfrew and Werfner's story exposes the pitfalls of

\footnotetext{
${ }^{4}$ Deleuze holds that "repetition is more a matter of coexistence than succession, which is to say, repetition is virtual more than it is actual" (Parr, 2012, p. 226).

5 Cohen Nookshaft sees Lew reading books on Bilocation and offers him some explanation, he says, "We are light, you see, all of light" and when "we lost our aetherial being and became embodied, we slowed, thickened, congealed to" this body. "The soul itself is a memory we carry of once having moved at the speed and density of light" (Against, p. 688). He holds that our soul is an aetherial and virtual being replete with virtual force of difference.
} 
an identity concept based on continuity in space over time" (p. 37). Dr. Ghloix, an alienist, talks to Lew and analyses the reason behind Renfrew/Werfner's manifestation as two rivals with contrary qualities. He believes this stems from an internal conflict within Renfrew/Werfner, "a rupture within a single damaged soul" which is reflected in the Renfrew and Werfner's stark opposition.

"This person Renfrew/Werfner appears afflicted [...] by a deep and fatal contradiction-deeper than consciously he can appreciate, and as a result the conflict has no other place to go but outward, ejected into the outside world [...] now obliged to suffer the disjunction in himself which he cannot, must not, admit... so pretending to be two 'rivals' representing the interests of two 'separate nations' which are much more likely secular expressions of a rupture within a single damaged soul.” (Against, p. 772)

Indeed, Dr. Ghloix thinks that this person is suffering from a deep contradiction so he decides to double himself so that the disjunction inside him could be bearable to him/them. Renfrew and Werfner seem to have co-consciousness as they are dealing with the same academic vocation, the same major, and the same research field. For both of them, "their shared interest in the Eastern Question had evolved from simple bickering-at-a-distance by way of the professional journals to true mutual loathing, implacable and obsessive, with a swiftness that surprised them both" (Against, p.254). Nonetheless, this mirror-like sameness does not imply identity, and "some symmetry [is] being broken. Violated" (Against, p.769). There are differences seen in this symmetrical relationship which shows the reality of difference as opposed to identity, their singularities, their being two separate existence. Up to a point in time, Renfrew/Werfner had been the same person, but with bifurcation they become two persons as the space-time becomes different for each of them. Given that--as Deleuze contends--time is difference, with time passing by, the identical persons will deviate more from each other in an unalienable manner. Therefore, they will go their separate ways after bilocation no matter how similar they are because the element of time which creates difference is inevitable. As the magician Zombini's practice of using double refraction to bifurcate people shows, to his consternation, the bilocation is not "reversible" because of "the element of time"; indeed, even "short couple of second" is "enough to make it impossible to get back to exactly where we'd been" (Against, p.400). Moreover, as Deleuze (1994) states, repetition is a conduct that is "necessary and justified [...] only in relation to that which cannot be replaced" which is "non-exchangeable and non-substitutable singularities" (p. 1). That is, the bilocation of Renfrew and Werfner, two people with "non-exchangeable and non-substitutable singularities", does not only question the concepts of continuity and sameness but also highlights the concept of difference and the branching possibilities it brings up. ${ }^{6}$

Moreover, Professor Edward Morley and Charles Morgan (aka M\&M) are also double-refracted; as Merle discovers, "It was so obvious! Professor Edward Morley and Charles 'Blinky' Morgan were one and the same person! Separated by a couple-three letters in name as if alphabetically double-refracted," and both have "long shaggy hair and big red mustaches" (Against, p.62). Yet again, there are some differences between them even if minor. Æther is to be "blame[d]" as well as light that "goes someplace else" and "takes a detour" (Against, p.62) thus creating the inevitable differences.

“[...] suppose when they split that light beam, that one half of it is Michelson's and the other is his partner Morley's, which turns out to be the half that comes back with the phases perfectly matched up [...]you could blame it on the Æther, sure, but other cases may be the light goes someplace else, takes a detour and that's why it shows up late and out of phase, because it went where Blinky was when he was invisible, and--" (Against, p.62)

For instance, one of the differences seen in the repetition of Morley/Morgan is the fact that "Blinky's a natty dresser, whereas Professor Morley's attire is said to exhibit a certain tendency to the informal" (Against, p. 62). Interestingly, this difference, "disparity", or "asymmetry" exists even for Blinky as such (who emerges "from invisibility" and "reenter[es]" the world) because each one of his eyes "saw the world differently" (Against, p. 62). In Deleuzian terms, these differences are because "in a very real sense, repetition is a creative activity of transformation" (Parr, 2012, p. 226), and to Deleuze, this is difference that allows for the prospect of the unique and the singular.

Further, several characters in the novel seem to be the virtual duplications of "Kieselguhr Kid" who is a spectral figure, a legendary anarchist whom the mining owners are after. One of these doppelgangers is Frank. Dwayne who is sent by a group of anarchists to find Kieselguhr Kid and seek help from him, once drops hints to Frank implying that he believes Kieselguhr Kid is actually Frank. Ellmore Disco and Bob Meldrum are also of the opinion that Frank is Kieselguhr Kid; the federal force which is after Kieselguhr Kid is also passing around photos of Frank as the legendary anarchist. However, Webb (and after his death, his soul) could also be the legendary Kieselguhr Kid because after Webb's death, the mine company is worried that Deuce have not managed to kill Webb at all since the bombings have continued without any interruption since then. Reef while driving to Telluride for taking his father's dead body, also ponders over the possibility of Webb's being Kieselguhr Kid. When he is thinking he might "carry on" this heritage of being the anarchist Kieselguhr Kid, he feels "some new presence inside him, growing, inflating" (Against, p. 214)

\footnotetext{
${ }^{6}$ Lew is also subject to the similar experience of difference and becoming. Once, he is reminded of his oblique past in Chicago and the crime he does not even remember. We learn that it was the bilocated Lew who had committed the unforgivable crime, but the actual Lew is paying for that; he wonders, "how much to some other version of Lew Basnight, bilocated off somewhere he could gain no clear sense of" (Against, p. 688). Moreover, in his dialogue with Renfrew, Lew realizes that Lew's bilocated self is having a dialogue with the bilocated self of Renfrew, i.e., Werfner. Lew asks him a question and has a sudden certitude that in Göttingen the bilocational Lew is asking Werfner the same question, and both "Lew Basnights" get "the same offended narrow stare" (Against, p. 690).
} 
which brings to mind the probability that being Kieselguhr Kid is now passed down to Reef from his father. He feels he is enjoying "a sort of dual existence, both in Socorro, and at the Pole" (Against, p. 215). Moreover, he is able to read a book aloud to his father's corpse in the absence of light without even noticing the darkness, and more importantly, nearly in the end of the book, years after Webb's death, Reef acknowledges his belief of "being the Kieselguhr Kid in Webb's place" (Against, p. 887). Although it is never clear who the Kieselguhr Kid is, the possibility that this spectral figure is Webb Traverse or his sons will remain open to the end of the novel. It is also possible that Kieselguhr Kid by turns resides in the souls of different people among them Traverses; suffice it to say, "As a power of the new, repetition calls forth a terra incognita filled with a sense of novelty and unfamiliarity" (Parr, 2012, p. 226). Moreover, the novel is replete with familial duplications, Web and his doubles Kit, Frank, and Reef; Reef and his younger double, Kit ("Kit and his own somehow aged or gravely assaulted double" [Against, p. 667]); and Merle and his daughter Dally who are very similar yet different: they "lived for different futures, but they were each other's unrecognized halves, and what fascination between them did come to pass was lit up, beyond question, with grace" (Against, p. 70). This genetic repetition of fathers in the kids is "the internal genetic elements of repetition" (Deleuze, 1994, p. 17) in which the virtualities of gene can unfold differently.

Also, among the abundant doublings is that of Chums of Chance and their Russian counterpart. The Chums of Chance encounter their Russian counterparts, "Tovarishchi Slutchainyi" that means accidental comrades in Russian. The "counterpart" of Inconvenience is "Bol'shaia Igra" which is led by Padzhitnoff.

It [the Bol'shaia Igra] was readily recognized by all as the flagship of Randolph's mysterious Russian counterpart - and, far too often, nemesis - Captain Igor Padzhitnoff, with whom previous "run-ins" (see particularly The Chums of Chance and the Ice Pirates, The Chums of Chance Nearly Crash into the Kremlin) evoked in the boys lively though anxious memories. (Against, p. 137)

That the parallel Chums are from the opponent country of Russia again shows the virtual power of difference in the repetitions in which difference privileges over identity and sameness. Indeed, like Deleuze, Pynchon tends to free repetition from mimesis since repetition is not the recurrence of the exact same thing as it is the site of emergence of pure difference. As Nathalie Aghoro (2009) sates in "Bilocated Identities: Taking the Fork in the Road in Against The Day," "The double presence of American and Russian national icons shows how their narrative identities shift between sameness and difference, between national representation and selfhood" (p. 39). That is, the dissimilarities in the duplicated Chums show that difference has a threatening effect on identity and sameness. At some point, the American Chums realize that the Tovarishchi Slutchainyi are themselves, yet ahead of them in time; that is, the force of time has caused the differences as time is difference from Deleuze's viewpoint.

"The travels of Captain Padzhitnoff [...] over the years, have pretty closely matched our own. No surprises there. But looking only at the months just before he disappeared, everyplace we'd been that year, ... old Padzhy's gone as well. Where we haven't been yet, he seems to have left no trace." (Against p. 1023)

Darby exclaims, "We're chasing ourselves now"; that is, the Tovarishchi are the future version of the Chums, very similar yet very different." Here the unity and continuity of identity is undermined since "repetition is a positive power (puissance) of transformation" (Parr, 2012, p. 226).

Justin Clair (2011) argues, "Perhaps the single most significant pairing in the novel is that of Scarsdale Vibe, the novel's central 'evil capitalist' caricature, and his double, Foley Walker" (p. 76); "the twin Vibes" (Against, p. 102) are another example of the novel's insistence that repetition is the virtual force of difference. Foley Walker had been Vibe's paid substitute to go to the Civil War instead of him. Years later, Foley feels that he has mental "communications from far, far away" with Vibe. He finds Vibe and becomes his closely attached companion for the rest of his life since, as Indians believe, "if you save the life of another, he becomes your responsibility forever" (Against, p. 101). Thus, they become undividable afterwards.

The Twin Vibes, as they soon came to be known, were sighted together often at Monmouth Park and Sheepshead Bay as well as tracks farther afield, togged out in matching sport ensembles of a certain canary-and-indigo check, screaming and waving fistfuls of betting slips - when they were not careering at excessive speeds up and down the avenues of Manhattan in a maroon phæton whose brass and nickelwork were kept rubbed to a blinding shine, side by side in their pale dusters, appearing to the unwary spectator as ineluctable as any other Apocalyptic Riders.

"So you could make a case," Foley concluded, "for me being more Scarsdale Vibe than Scarsdale Vibe himself." (Against, p. 102)

Foley Walker, once the physical representative of Vibe, his body double, is now his "deputy of Wealth" and merges his identity with Vibe's; as he puts it, "I am he" (Against, p. 99). Yet, Vibe and Foley, although very similar, are very different at the same time as "repetition is produced via difference, not mimesis" (Parr, 2012, p. 225). Folly is a secular and strong-willed person, as Folly himself says, his nerves are "cast iron" while Vibe is obsessed with his own interpretation of Christian sense of duty "isolated in self resonant Fantasy" (Against, p. 333). The more we further in the story, the more we notice these differences between the two. Thus, the twinship, this "being more Scarsdale Vibe than Scarsdale Vibe himself” (Against, p. 102) as mysteriously deep as it is, is not to last forever. As Deleuze, while offering some examples of repetition, says, "Reflections, echoes, doubles and souls do not belong to the domain of resemblance or equivalence; and it is no more possible to exchange one's soul than it is to substitute real twins for one another" (1994, p.1). Thus, Foley starts questioning their twinship. Talking to himself he says, "You suffered through the 
Wilderness and at last, at Cold Harbor, lay between the lines three days, between the worlds, and this is what you were saved for? This means, nervous, scheming servitude to an enfeebled conscience?" (Against, p. 335) and finally, in the last pages of the novel he becomes a "born-again Christer" (Against, p. 1004) and kills Vibe when Vibe asks Foley to protect him against vengeful Frank who intends to kill Vibe.

Even in a town full of murderous Anarchists who hated him worse than Rockefeller, Scarsdale had seen no need to walk around these streets heeled. In his accustomed tone of command, at exactly the moment he should not have adopted it, he now barked, "Well you see them as clearly as I do, Foley. Take care of it." In reply, smoothly as if it were another long-practiced personal chore, Foley stepped away swiveling, lined up the Luger's muzzle with his employer's heart, and chambered the first round. Scarsdale Vibe peered back, as if only curious. "Lord, Foley ...” (Against, p. 1006)

When, all of a sudden, Folly shoots Vibe instead of shooting his enemy, we are still shocked. Yet, this abrupt killing reveals the differences between the two seemingly indistinguishable characters even more. Foley Walker being "the 'other' Scarsdale Vibe" claims his differential existence by killing Vibe, showing that he is not a mere copy; as Deleuze holds, repetition is "the possibility of reinvention, that is to say repetition dissolves identities as it changes them, giving rise to something unrecognisable and productive" (Parr, 2012, p. 224). Namely, the only thing that is repeated is difference. Scarsdale's death can, therefore, be seen as an analogy for the complicated concept of identity and difference.

Yet, one of the most fascinating and significant examples of duplications in the novel is related to Stupendica, a ship which has the capacity to duplicate itself. Going to Europe, Merle Rideout's daughter Dally and her mother Erlys along with Zombinis are aboard the Stupendica, the ocean liner. Another passenger aboard the Stupendica ship is Kit who is going to Göttingen to study mathematics. Stupendica has the ability to split into two vessels; it can be transformed into S.M.S. Emperor Maximilian a 25,000 ton battleship of the Austro-Hungarian Navy. Originally, the two ships were adjoined just at a "deeper level"; that is, the Engine Room (Against, p. 519). Indeed, these two ships were being made as two different projects in different places but they "merged" into a "single ship" whose "How? At whose behest?" (Against, p. 517) were known by no one. While Dally and Kit are abroad, the ship is assaulted by a torpedo, then it bifurcates into Emperor Maximilian ship. Kit is trapped in the engine room where he finds out that the Stupendica is pregnant with another ship. Stupendica, which has received a message in cipher "from somewhere else not quite 'in' the world", starts its metamorphosis and the "entire decks began ponderously to slide, fold, or rotate, and passengers found themselves, often lethally, in the way of this booming and shrieking steel metamorphosis" (Against, p. 518). And,

The ship itself splits in two, and sailors comically tear off their uniforms to reveal the get-up of naval ratings. The ship, for a moment maintains a dual identity, one briefly transposed over the other before they split. As the chief Oberhauptheitzer says: “...there are no staterooms, it is no longer the Stupendica up there. That admirable vessel has sailed on to its destiny. Above decks now you will only find His Majesty's dreadnought, Emperor Maximilian. It is true that for a while the two ships did share a common engine room. A 'deeper level' where dualities are resolved." (Against, p. 519)

Dally has been taken by the other half of the ship to the Counter-Venice and is curious what has happened to Kit, unaware of the fact that "she and Kit were on separate vessels, distinct versions of the Stupendica, pulling away slowly on separate courses, each bound to a different destiny" (Against, p. 514). The bilocated Kit takes an electric tram to a hotel "where for some reason he assumed there'd be a room reserved and waiting" (Against, p. 525). Then, all of a sudden, he runs into Root Tubsmith whom he lost in the Stupendica, and Kit says, "Nothing's been rigorously what you'd call 'real' lately. Does seeing you in this condition mean that everything is normal again?" to which Root answers, "Of course" (Against, p. 535); as if, lately, Kit has been in a bilocated world or parallel universe and the actual world by turns.

Later, the narrator mentions that after 1914 (when World War One is looming), "The Stupendica's destiny was to reassume her latent identity as the battleship S.M.S. Emperor Maximilian" which was "one of several 25,000-ton dreadnoughts contemplated by Austrian naval planning but, so far as official history goes, never built" (Against, p. 515). This actual, "official", or sedentary history is different from the virtual, nomadic, alternate reality in which the Stupendica can bifurcate. In fact, Bilocation and the splitting of paths are also Pynchon's techniques to propose the concept of alternative history or the virtual possibilities of history. Clair (2011) also argues, "As any reader of Against the Day can attest, however, the novel's obsession with doubles extends far beyond issues of characterization and corporate citizenship. Spaces, places, and even history itself seem to double back and reduplicate" (p. 76). In Against the Day, several Characters and things are doubled, and this is Pynchon's means of disturbing the traditional sense of human history with traditional space-time dimensions. Pynchon's strong passion for dyads and metaphors of duality, which is more evidently reflected in the twinned characters (like Webb and Kieselghur Kid, Professors Renfrew and Professors Werfner, Nigel and Neville, Pino and Rocco, Frank and Reef and other multiple personas and bilocated persons) transgresses these bilocations and twinships to other deeper concepts like time, space, and history, for instance, through revealing virtual localities inside the actual one (such as the sub-desertian cities of North Pole, the counter earth, the "Inner Asia" of Asia, the "Deep Germany" of Germany [Against, p. 661]). Hence, the counter historical figures and events, the binocular events, the dual temporalities, and in a word, the theme of bilocation--since Bilocation entails a person or an event in two places at one time--disrupt the fixed territorial and temporal dimensions as well as actual dimensions while transcending secular time and space. 


\section{Iceland Spar, Double-Refraction and Revealing the World Beyond}

Another representation of Pynchon's obsession with duality is the doubling effect Iceland spar, a calcite which has the qualities of "Deep wisdom, ancient truth, light from beyond" (Against, p. 391). Besides bifurcated twins and twin worlds mentioned throughout the novel, the fact that part two of Against the Day is entitled "Iceland spar" and starts with the introduction of the Chums' doppelgangers, as well as the book's cover image which portraits an Iceland spar bifurcating the words of the title via double refraction, show the significance of the theme in the novel. Indeed, Iceland spar and its doubling effect which have been the main motives of the novel can provide the reader with a visual metaphor for the whole novel as such since the novel also reveals the multidimensionality of the reality of the world and showcases the virtual aspects of actual events, entities, and people. That is to say, the reader is left with a doubly refracted reality of the world through the prism of Against the Day. As Seán Molloy (2010) argues, Pynchon implies that "the expansion of possibility" caused by dual refraction is a glimmer of hope for avoiding the doom; he states, "Despite the gloomy prognosis of Pynchon as regards the future of 'the' Earth, he does not quite abandon hope. Mankind is spared certain doom by the expansion of possibility due to the operation of dual refraction and the warping of space and time as the Earth traverses the universe" (p. 13).

The calcite is "a different form of calcium carbonate - namely, to microscopic crystals of the doubly-refracting calcite known as Iceland spar" (Against, p. 114). It can duplicate images and enable bilocation; indeed, its extraterrestrial properties and functions are gained through double refraction, and several fantastic devices and deeds become possible by dint of the its virtual quality. ${ }^{7}$ The fact that the calcite has the transcendent potentiality to doubly refract light, enables it to create an aspect of the object viewed through it which is beyond the ordinary, actual aspect that human's eye can perceive, that is the virtual side of the object hidden from the bare eyes. Whatever is observed through the Iceland spar is produced as a double dimmer image. Through the prism of the calcite, the actual light refracts into actual virtual divisions revealing the potentially hidden forces inside any entity; when you look through a pure enough specimen of Iceland spar you can see "not just the man but his ghost alongside him', a vision of a multitude of worlds that is "either horrifying or amazing" (Against, p. 375). Through the lenses, prisms, or mirrors made of this double-refracting "ghostly mineral", "certain "invisible' lines and surfaces" can become "accessible" and actual.

Sometime before the first report of it in 1669, calcite or Iceland spar had arrived in Copenhagen. The double-refraction calcite having been noticed immediately, the ghostly mineral was soon in great demand among optical scientists across Europe. At length it was discovered that certain "invisible" lines and surfaces, analogous to conjugate points in two-dimensional space, became accessible through carefully shaped lenses, prisms, and mirrors of calcite, although the tolerances were if anything even finer than those encountered in working with glass, causing artisans by the dozens and eventually hundreds to join multitudes of their exiled brethren already wandering the far landscapes of madness. (Against, p. 250)

Indeed, Pynchon assigns a paranormal value to double refraction and depicts it in several points in the story as more than merely the optical phenomenon of light being refracted and the image of things being split. As the narrator explains, the ordinary light passes through this calcite and is split into two separate rays "termed "ordinary' and "extraordinary" enabling the scientists to "create an additional channel of optical communication" (Against, p. 114). Moreover, another mysterious quality that the calcite has due to double-refraction is that it can function like the magician's globe. El Espinero gives Frank "a twin crystal, pure, colorless, without a flaw" and invites him to look into the spar and "see things" (Against, p. 391). In the depth of a dark cavern, the calcite is filled with "some queer luminescence" and Frank sees Sloat Fresno and his place (Against, p. 391). That is, the "deep wisdom, ancient truth, light from beyond" related to the calcite foreshadows what is going to happen soon, that Frank will accidentally see Sloat in a cantina and manages to take his father's revenge by killing him. Further, using the "damned Magic Crystal" (Against, p. 133) and its ability for double refraction, one actual person can be split into two persons who are two manifestation of the virtual existence of one person in two persons. The magician Luca Zombini, while is taking out a crystal of Iceland spar says that it

Doubles the image, the two overlap, with the right sort of light, the right lenses, you can separate them in stages, a little further each time, step by step till in fact it becomes possible to saw somebody in half optically, and instead of two different pieces of one body, there are now two complete individuals walking around, who are identical in every way, capisci? (Against, p. 355)

Iceland spar, which has a "Mineral consciousness" (Against, p. 133), can reveal the hidden aspects of things, "the architecture of dream", and it can escape from the frame of the actual by going beyond the "network of ordinary latitude and longitude" (Against, p. 250). As Professor Svegli explains to Chums, "if one accepts the idea that maps begin as dreams, pass through a finite life in the world, and resume as dreams again," "these paramorphoscopes of Iceland spar, which cannot exist in great numbers if at all, reveal the architecture of dream, of all that escapes the network of ordinary latitude and longitude" (Against, p. 250). The calcite even can help people read texts "Outside of time" or "[i]n a different relation to time"; Chums use "an optically-perfect sheet of Iceland spar" (437) to read the cryptic Itinerary to Shambhala which was indeed a "strangely-distorted and only partly-visible document" (Against, p. 437). Also, Iceland spar has the capacity to make people invisible, as it does with the hidden people who live in their private rock

\footnotetext{
7 Moreover, The Book of Iceland Spar, which is a magical book telling its readers "even of days not yet transpired," is to be read through Iceland spar. As the Librarian says to the Chums, The Book of Iceland Spar reveals "the sub-structure of reality" (Against, p. 133). The book is the "doubling of the Creation, each image clear and believable."
} 
dwellings:

Iceland spar is what hides the Hidden People, makes it possible for them to move through the world that thinks of itself as "real," provides that all-important ninety-degree twist to their light, so they can exist alongside our own world but not be seen. They and others as well, visitors from elsewhere, of non-human aspect. (Against, p. 134)

Using Iceland spar's double-refraction that twists light and "can polarize light not only in space but in time as well", the hidden people can remain invisible to human eyes. For generations, the people have been passing humans and commuting between the alternate worlds without humans' noticing them. Simply put, Iceland spar, the polarizing filter, generates a refractory image of anything that is looked at through its prism. This potentiality references many virtual aspects that are hidden in the entities and human beings like the ability of things and humans to be doubled or multiplied in time and place, the ability to go beyond actual time and space, and the possibility of parallel universes and alternate worlds.

\section{CONCLUSION}

In Against the Day, Pynchon shows a strong penchant for duality, bilocation, and duplication. In Difference and Repetition, Deleuze states, "Repetition is not generality"; that is, as we also see in Against the Day, in differential repetition, although the two objects or subjects share generalities, there are always differences which makes them "non-exchangeable and non-substitutable" (1994, p.1) singularities; this is because each particular being follows various paths of development. Therefore, repetitions reproduce difference and singularity, not identity or sameness. It is noteworthy that, the whole book of Difference and Repetition with all its intricate content, could be considered as a critique of identity. In this novel, each time the repetitions create a differential genetic condition in which there is an indviduation of a definite entity or person for example, Werfner/Renfrew pair, Vibe and Foley, Zombini's duplications, Lew and his duplication, Professor Morley and Morgan, Kieselguhr Kid and his personifications, Chums of Chance and their Russian counterpart, as well as Stupendica and the battleship S.M.S. Emperor Maximilian. These are doubling up of identities since the duplication not only is concerned with continuity in space but with time as well. Moreover, one of Pynchon's major leitmotifs is the mysterious calcite of Iceland spar and its promising ability of double refraction. The potentiality to doubly refract light creates a double image and allows for revealing things beyond the ordinary, actual realm that human's eye discerns. Pynchon, even, undermines the traditional and sedentary history as well as traditional space-time conceptions with the counter historical figures and events, the dual temporalities, and the binocular events he creates throughout the novel.

\section{REFERENCES}

[1] Aghoro, N. (2009). Bilocated Identities: Taking the Fork in the Road in Against The Day. Aspeers, 2, 33-52.

[2] Clair, J. (2011). Binocular Disparity and Pynchon's Panoramic Paradigm. In Pynchon's Against the Day: A Corrupted Pilgrim's Guide (pp. 67-91). Newark: University of Delaware.

[3] Colebrook, Claire. (2002). Gilles Deleuze. London: Routledge.

[4] Deleuze, Gilles. (1989). Cinema 2: The Time Image. Trans. Hugh Tomlinson. Minneapolis: University of Minnesota.

[5] Deleuze, Gilles. (1994). Difference and Repetition. Trans. Paul Patton. New York: Columbia University Press.

[6] Elias, Amy J. (2011). Plots, Pilgrimage, and the Politics of Genre in Against the Day. In Pynchon's Against the Day: A Corrupted Pilgrim's Guide (pp. 29-47). Newark: University of Delaware.

[7] Molloy, S. (2010). Escaping the Politics of the Irredeemable Earth-Anarchy and Transcendence in the Novels of Thomas Pynchon. Theory \& Event 13(3), Johns Hopkins University Press. Retrieved April 28, 2018, from Project MUSE database.

[8] Narkunas, Paul. (2011). Europe's "Eastern Question" and the United States' "Western Question": Representing Ethnic Wars in Against the Day. In Pynchon's Against the Day: A Corrupted Pilgrim's Guide (pp. 239-264). Newark: University of Delaware.

[9] Parr, A. (2012). The Deleuze dictionary. Edinburgh: Edinburgh University Press.

[10] Pynchon, Thomas. (2006). Against the Day. New York: Penguin.

[11] Spinks, Lee. (2012). Eternal Return. In The Deleuze Dictionary (pp. 85-87). New York: Columbia University Press.

[12] Stangoll, Cliff. (2012). Difference. In The Deleuze Dictionary (pp. 74-76). New York: Columbia University Press.

\footnotetext{
Ali Salami, PhD. is a literary scholar, lexicographer and Assistant Professor of English literature at the University of Tehran. An internationally published author, Salami has written extensively on gender and discourse, Shakespeare and postcolonial literature. He is the author of Shakespeare and The Reader (Chicago, 2013) and the editor of Culture-Blind Shakespeare (Newcastle, 2015) and Fundamental Shakespeare (Newcastle, 2015). He has translated six volumes of Persian poetry into English. His 21st century translation of The Magnificent Qur'an was published by Leilah Publications in the USA. Some of Salami's writings have been translated into a number of languages.
}

Razieh Rahmani is a Ph.D. candidate in English Language and Literature at University of Tehran. Her research mainly focuses on literary theory, Deleuze, contemporary novels, and Pynchon. She has published a number of articles on Beckett and Doctorow; also, she has translated some of Kurt Vonnegut's works into Persian. 